\title{
Article \\ A Longitudinal Assessment of Risk Factors and Chronic Diseases among Immigrant and Non-Immigrant Adults in Australia
}

\author{
Mehwish Nisar ${ }^{1, *(\mathbb{D})}$, Tracy L. Kolbe-Alexander ${ }^{2,3,4} \mathbb{D}$, Nicola W. Burton ${ }^{5}$ and $^{-}$Asaduzzaman Khan $^{1}(\mathbb{D}$ \\ 1 School of Health and Rehabilitation Sciences, The University of Queensland, Brisbane 4072, Australia; \\ a.khan2@uq.edu.au \\ 2 School of Human Movement and Nutrition Sciences, The University of Queensland, Brisbane 4072, Australia; \\ tracy.kolbe-alexander@usq.edu.au \\ 3 School of Health and Wellbeing, University of Southern Queensland, Ipswich 4350, Australia \\ 4 Division of Exercise Science and Sports Medicine, Department of Human Biology, Faculty of Health Sciences, \\ University of Cape Town, Rondebosch, Cape Town 7700, South Africa \\ 5 School of Applied Psychology, Griffith University, Brisbane 4122, Australia; n.burton@griffith.edu.au \\ * Correspondence: m.nisar@uq.net.au; Tel.: +61-42615-3430
}

check for

updates

Citation: Nisar, M.; Kolbe-Alexander T.L.; Burton, N.W.; Khan, A.

A Longitudinal Assessment of Risk

Factors and Chronic Diseases among Immigrant and Non-Immigrant Adults in Australia. Int. J. Environ. Res. Public Health 2021, 18, 8621. https://doi.org/10.3390/ijerph18168621

Academic Editors: Thomas E. Dorner and Igor Grabovac

Received: 12 June 2021

Accepted: 12 August 2021

Published: 15 August 2021

Publisher's Note: MDPI stays neutral with regard to jurisdictional claims in published maps and institutional affiliations.

Copyright: (c) 2021 by the authors. Licensee MDPI, Basel, Switzerland. This article is an open access article distributed under the terms and conditions of the Creative Commons Attribution (CC BY) license (https:/ / creativecommons.org/licenses/by/ $4.0 /)$.

\begin{abstract}
This study aimed to investigate the prevalence and trajectories of chronic diseases and risk behaviors in immigrants from high-income countries (HIC), low-middle-income countries (LMIC), to Australian-born people. Data were used from five waves of the HABITAT (2007-2016) study11,035 adults living in Brisbane, Australia. Chronic diseases included cancer, diabetes mellitus, coronary heart disease, and chronic obstructive pulmonary disease (COPD). Risk factors assessed were body mass index (BMI), insufficient physical activity, and cigarette smoking. Diabetes mellitus increased in all groups, with the highest increase of 33\% in LMIC immigrants. The prevalence of cancers increased $19.6 \%$ in the Australian-born, $16.6 \%$ in HIC immigrants, and 5.1\% in LMIC immigrants. The prevalence of asthma increased in HIC immigrants while decreased in the other two groups. Poisson regression showed that LMIC immigrants had 1.12 times higher rates of insufficient physical activity, 0.75 times lower rates of smoking, and 0.77 times lower rates of being overweight than the Australian-born population. HIC immigrants had 0.96 times lower rates of insufficient physical activity and 0.93 times lower rates of overweight than Australian-born. The findings of this study can inform better strategies to reduce health disparities by targeting high-risk cohorts.
\end{abstract}

Keywords: immigrants; chronic disease; risk factors; Australia

\section{Introduction}

Chronic diseases are responsible for up to 70\% of deaths worldwide [1]. According to the World Health Organization (WHO), the major chronic diseases are divided into four groups: heart disease, cancer, diabetes, and chronic obstructive pulmonary disease (COPD) [2]. These chronic diseases share common risk factors, including cigarette smoking, alcohol abuse, unhealthy diet, excess weight, and insufficient physical activity [3]. Tobacco smoking, excessive weight, and physical inactivity are the three main modifiable key risk factors that contribute substantially to the economic burden associated with chronic diseases. A modest annual 1\% relative reduction in the prevalence of tobacco smoking, excess weight, and physical inactivity can reduce an annual $\$ 8.5$ billion overall economic burden of chronic diseases [4].

Chronic diseases are responsible for $89 \%$ of all deaths in Australia [5]. One in two $(50 \%)$ Australians have at least one of the following chronic diseases: arthritis, asthma, musculoskeletal problems, cancer, cardiovascular disease, COPD, diabetes, and mental health conditions [6]. In 2019, 11.6\% of adults smoked daily while $15.6 \%$ of adults reported 11 or more alcohol drinks on 1 occasion at least once a year [7]. An estimated two in three 
adult Australians were overweight or obese and more than half of adults (55\%) were not sufficiently active [7]. Tobacco smoking and alcohol use are responsible for $9 \%$ and $5.1 \%$ of the total burden of disease in the Australian population. Insufficient physical activity is associated with $10 \%$ and $20 \%$ of the disease burden of major chronic diseases [8].

Immigrants account for $29.7 \%$ of the Australian population [9]. Previous studies have shown that there is a large variation in the prevalence of chronic disease and modifiable risk factors in the Australian immigrant population [10]. Epidemiological data in Australia indicate that the disproportionate burden of disease among ethnic groups depends primarily on the country of origin, culture, language, and duration of stay in Australia. In particular, the different health behaviors and social needs of immigrants from low and high-income countries significantly impacted their overall well-being. The difference in the prevalence of chronic disease risk factors by country of birth was largely linked with their different financial circumstances. A large cross-sectional study of 264,102 Australians demonstrated that immigrants born in the high-income countries (HIC), had a higher mean chronic disease risk index than Australian-born participants, and immigrants from low-middle-income countries (LMIC), had a lower mean chronic disease risk index than Australian-born participants [11]. One study comparing ethnic groups reported that Sri Lankan/Bhutanese and Pacific Islander people were more likely to be hypertensive than other immigrant groups [12]. It was also reported that gestational diabetes is higher among pregnant women from South Asia (15.0\%), Africa (9.4\%), Vietnam (7.3\%), than women born in Australia and New Zealand (4.3\%) [13]. It is therefore important to differentiate between high and low/middle-income countries when studying immigrants' health.

Most studies investigating the health of immigrants are cross-sectional, which only provides a snapshot in time of the differences between immigrants and Australian-born groups [11,12]. A small number of prospective studies have compared the incidence of chronic disease in immigrants and Australians [14]. However, none of these studies included a longitudinal assessment of the prevalence of chronic diseases and associated behavioral risk factors of immigrants from LMIC, HIC, and Australian-born people. This information is needed to identify the high-risk groups to be targeted for health care planning for chronic conditions. The aims of this study were, therefore, (a) to compare levels of chronic diseases and modifiable risk factors between Australian-born participants, low-middle-income countries (LMIC), and high-income countries (HIC) immigrant groups in a random sample of mid-aged and older adults living in Brisbane, Australia, and (b) to examine the trajectories of these diseases and risk factors over nine years. In this study, we focused on three modifiable risk factors: high body mass index, insufficient physical activity, and cigarette smoking; and four major chronic diseases, including cancer, diabetes mellitus, heart disease, and COPD (emphysema/chronic bronchitis and asthma).

\section{Methods}

\subsection{Setting and Recruitment}

The data used in this analysis were from the HABITAT(How Areas in Brisbane Influence HealTh and AcTivity) study [15], which is a longitudinal, multilevel study that conducted a mail survey at five points approximately two years apart $(2007,2009,2011$, 2013, and 2016) in Brisbane. The 2016 census showed that 32.2\% of Brisbane's inhabitants were born overseas [16]. Migration streams in Brisbane are close to the national average (33.3\% in 2016), which makes it a useful city for understanding immigrant health status in Australia [16]. The sampling and recruitment strategy for the HABITAT study has been detailed elsewhere [15]: a structured self-administered mail survey was first sent in May 2007 to 17,000 people (aged between 40 and 65 years), and 11,035 usable surveys were obtained, yielding a baseline response rate of $68.3 \%$ [15]. The corresponding response rates from eligible and contactable participants in 2009, 2011, 2013 and 2016 were $72.6 \%, 67.3 \%$, $67.1 \%$ and $58.8 \%$, respectively. The HABITAT study received ethical clearance from the Queensland University of Technology Human Research Ethics Committee (Ref. no. 3967H and 1300000161). 


\subsection{Measures}

\subsubsection{Sociodemographic Measures}

Individual-level sociodemographic measures included gender, age, educational qualifications, employment status, gross annual household income, and country of birth.

\subsubsection{Chronic Diseases}

Health measures were derived from questionnaire items assessing global health status, and previously diagnosed chronic health diseases. Chronic diseases were assessed with the question, "Have you ever been told by a doctor or nurse that you have any of the long-term health diseases listed below? Please only include those diseases that have lasted, or are likely to last, for the last six months or more". This list included asthma, any type of cancer, chronic bronchitis/emphysema, type 2 diabetes, heart/coronary disease. The answer required a yes/no response.

\subsubsection{Risk Factors}

Physical activity (PA) was assessed using items from the Active Australia Survey to indicate time spent in the previous week [17]. Responses were quantified in MET$\mathrm{min} /$ week as ([walking minutes $\times 3 \mathrm{METS}]+$ [moderate minutes $\times 3 \mathrm{METS}]+$ [vigorous minutes $\times 7.5$ METS]), and categorized into one of two categories: $\geq 600$ MET-Min/week for sufficient PA and <600 MET-min/week for insufficient PA [18]. Smoking status was assessed by asking "Which ONE of the following best describes your cigarette smoking?" Response options were, "I smoke daily", "I don't smoke now, but I used to", "I smoke occasionally", and "I have never smoked". Body mass index (BMI) was calculated using the self-reported height and weight and divided into three categories: BMI $<25=$ healthy weight, BMI 25-<30 = overweight, and BMI $\geq 30=$ obese.

\subsubsection{Ethnicity}

Participants self-reported their country of birth in response to the questions "Were you born in Australia?" and "If you were born in another country, where?" The World Bank country classification [19], by income group, was used to classify the country of birth of those participants who indicated they were not born in Australia. Because of known differentiated health effects of migration from LMIC to HIC, and HIC to HIC countries, the participants were divided into three groups based on their country of birth: (a) Australian-born, (b) immigrants from HIC and (c) immigrants from LMIC.

\subsection{Data Analysis}

Five waves of the HABITAT survey data were analyzed to determine the prevalence of self-reported chronic diseases and behavioral risk factors over 9 years by group country of birth: Australian-born, immigrants from high-income countries, and immigrants from low-middle-income countries. Poisson regression was used to estimate the prevalence ratios (PRs) because of its ability to estimate PR consistently and effectively in prospective studies. Poisson regression provides better analysis than logistic regression because of providing unbiased, more interpretable, and easier to communicate ratios [20]. To avoid overestimating the error of the estimated risk, a robust error variance procedure (sandwich estimation) was used (Zou, 2004). Preliminary bivariate analyses indicated that employment status, income, and education qualifications were not significantly associated with any of the diseases or risk factors under study. All regression models were adjusted for age, sex, education, and gross household income. All socio-demographic covariates analysed are listed in Table 1. We reported estimated PRs with 95\% confidence intervals (CIs) at a significance level of $p<0.05$. All analyses were conducted using Stata 14.0 SE. 
Table 1. Sociodemographic and health characteristics of the analytical sample at baseline $(n=11,035), 2007$.

\begin{tabular}{|c|c|c|}
\hline Characteristics & $n$ & $\%$ \\
\hline \multicolumn{3}{|c|}{ Sex } \\
\hline Male & 4942 & 45.0 \\
\hline Female & 6093 & 55.0 \\
\hline \multicolumn{3}{|c|}{ Age (years) } \\
\hline $42-44$ & 2530 & 23.0 \\
\hline $45-49$ & 2382 & 21.0 \\
\hline $50-54$ & 2312 & 21.0 \\
\hline $55-59$ & 2080 & 19.0 \\
\hline $60-65$ & 1731 & 16.0 \\
\hline \multicolumn{3}{|c|}{ Country of birth * } \\
\hline Australia & 8245 & 75.0 \\
\hline High-income countries (HIC) & 1704 & 16.0 \\
\hline $\begin{array}{l}\text { Low-middle-income } \\
\text { countries (LMIC) }\end{array}$ & 1011 & 9.0 \\
\hline \multicolumn{3}{|c|}{ Employment status } \\
\hline Full-time work & 5846 & 53.0 \\
\hline Part-time work & 1771 & 16.0 \\
\hline Home duties & 683 & 6.0 \\
\hline Unemployed & 160 & 1.0 \\
\hline Other & 51 & 0.4 \\
\hline \multicolumn{3}{|c|}{ Highest educational qualification } \\
\hline School only (up to 12 years) & 4311 & 39.0 \\
\hline Certificate/diploma & 3220 & 29.0 \\
\hline University degree & 3457 & 32.0 \\
\hline \multicolumn{3}{|c|}{ Gross annual household income (AUD) } \\
\hline$\$ 0-41599$ & 2232 & 24.0 \\
\hline$\$ 41,600-72,799$ & 2438 & 26.0 \\
\hline$\$ 72,800-129,000$ & 2845 & 30.0 \\
\hline$\$ 130,000+$ & 1889 & 20.0 \\
\hline \multicolumn{3}{|c|}{ General health status } \\
\hline Excellent & 1117 & 10.0 \\
\hline Very good & 3670 & 34.0 \\
\hline Good & 4194 & 38.0 \\
\hline Fair & 1575 & 15.0 \\
\hline Poor & 375 & 3.0 \\
\hline \multicolumn{3}{|c|}{ Body mass index (BMI) } \\
\hline Healthy weight $(<25)$ & 4369 & 41.5 \\
\hline Overweight $(25-<30)$ & 3900 & 37.1 \\
\hline Obese $(\geq 30)$ & 2248 & 21.4 \\
\hline
\end{tabular}

\section{Results}

\subsection{Participant Sociodemographic Characteristics}

A summary of the sociodemographic variables of the HABITAT participants in wave 1 (baseline) (2007) is provided in Table 1. The average age was 51.04 (SD 7.06) years, and more than half of the respondents were women (55\%). A quarter (25\%) of the participants were born outside of Australia, with 16\% from HICs and $9 \%$ from LMICs. Less than half of the participants (44\%) considered their general health to be either "very good" or "excellent", and 18\% reported their health as fair to poor (Table 1). 


\subsubsection{Chronic Diseases}

The prevalence of all chronic diseases (type 2 diabetes, heart/coronary disease, emphysema, and all types of cancer) increased over the nine years in all groups; the exception was asthma, which showed a decrease in LMIC and Australian-born groups. Diabetes mellitus increased in all groups, with the highest increase of 33\% in LMIC immigrants (Figure 1a). The increased prevalence of any type of cancers was consistently higher among participants born in Australia (8.1\% in 2007 to $27.7 \%$ in 2016) and immigrants from HICs (6.1\% in 2007 to $22.7 \%$ in 2016) than those from LMICs (2.9\% in 2007 to $8.0 \%$ in 2016). There was a decrease in the prevalence of asthma from $8.9 \%$ to $6.4 \%$ in LMIC immigrants, and from $14.4 \%$ to $14.2 \%$ in Australian-born, but an increase in HIC immigrants from $11.1 \%$ to $11.5 \%$ over nine years.
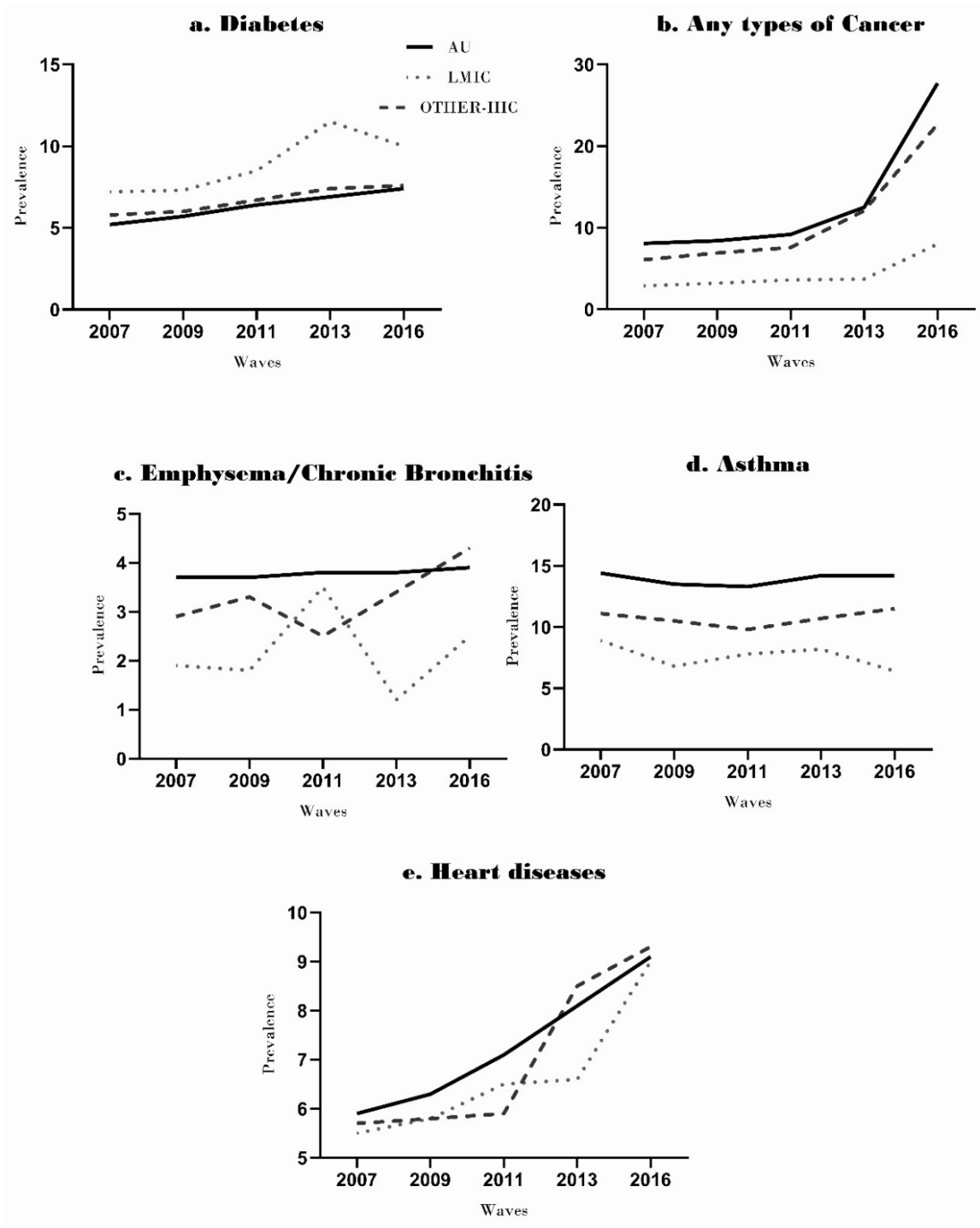

Figure 1. Prevalence of chronic diseases of immigrants (High-income countries and Low-middleincome countries) and Australian born people across five waves: 2007-2016 (a) prevalence of diabetes across five waves (b) prevalence of cancer across five waves (c) prevalence of emphysema/chronic bronchitis across five waves (d) prevalence of asthma across five waves (e) prevalence of heart diseases across five waves.

The overall prevalence of emphysema increased in all groups: LMIC immigrants $(1.9 \%$ in 2007 to $2.5 \%$ in 2016), HIC immigrants (2.9\% in 2007 to $4.3 \%$ in 2016) and Australian-born participants (3.7\% in 2007 to $3.9 \%$ in 2016). However, the prevalence of emphysema showed 
a slight decline in some time points from previous values including, LMIC immigrants (wave 2 and wave 4), and HIC immigrants (wave 3), and Australian-born participants (wave 5) (Figure 1d). The prevalence of heart disease increased in all groups from 5.5\% to $9.0 \%$ for LMIC immigrants, $5.7 \%$ to $9.3 \%$ for HIC immigrants, and $5.9 \%$ to $9.1 \%$ for Australian-born participants.

With the adjusted regression analysis, we found that LMIC immigrants had 1.02 times (95\% CI 1.00-1.03) higher PRs of diabetes mellitus than Australian-born participants, while HIC immigrants showed similar rates as Australian-born participants. The PRs of emphysema 0.98 (95\% CI 0.97-0.99), asthma 0.95 (95\% CI 0.94-0.95) and cancers 0.93 (95\% CI 0.92-0.95) were significantly lower in LMIC immigrants than Australian-born participants $(p<0.001)$. In HIC immigrants, the rates of emphysema 0.99 (95\% CI 0.98-1.00) and asthma 0.98 (95\% CI 0.96-0.99) were like the Australian-born participants (Table 2). Conversely, the rates of cancers 0.97 (95\% CI 0.96-0.99) were significantly lower in HIC immigrants than the Australian-born participants (Table 2). The rates of heart diseases did not show any statistically significant difference between Australian-born, LMIC, and HIC immigrant groups.

\subsubsection{Risk Factors}

Insufficient PA was consistently higher at each time point among LMIC immigrants (53.2\% in 2007 to $44.9 \%$ in 2016) than HIC immigrants ( $43.4 \%$ in 2007 to $38.4 \%$ in 2016) and their Australian-born counterparts (47.1\% in 2007 to $41.3 \%$ in 2016) (Figure 2a). The prevalence of overweight and obese peoples increased over nine years in LMIC immigrants (from $43.0 \%$ in 2007 to $55.0 \%$ in 2016), Australian-born (60.8\% in 2007 to $64.3 \%$ in 2016) and HIC immigrant (56.4\% in 2007 to 61.9\% in 2016) (Figure 2b). The prevalence of smokers declined in all groups during the nine years. Smoking decreased more in HIC immigrants (14.9\% in 2007 to $7.2 \%$ in 2016) than the Australian-born (16.5\% in 2007 to $7.4 \%$ in 2016) and LMIC immigrants (12.2\% in 2007 to $6.4 \%$ in 2016) (Figure 2c).
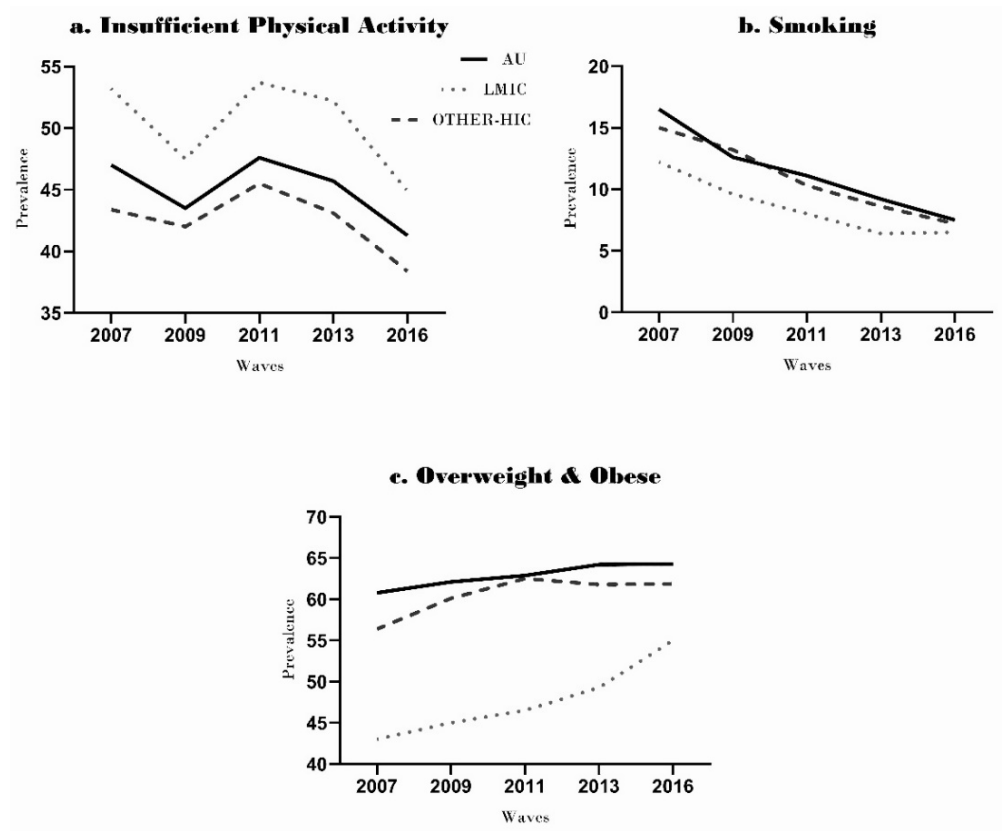

Figure 2. Prevalence of risk factors of immigrants (High-income countries and Low-middle-income countries) and Australian born people across five waves: 2007-2016. (a) prevalence of insufficient physical activity across five waves (b) prevalence of smoking across five waves (c) prevalence of overweight \& obese across five waves.

With Poisson regression, we found that the rates of insufficient PA were significantly higher in LMIC immigrants $(1.12 \%, 95 \%$ CI 01.06-1.18; $p<0.001)$ than the Australian-born participants (Table 2). However, the rates of insufficient physical activity were similar in 
HIC immigrants and Australian-born people. The rates of smoking 0.75 (95\% CI 0.63-0.91) and overweight participants 0.75 (95\% CI 0.63-0.91) were significantly lower in LMIC immigrants than the Australian-born group. The PRs of overweight and obesity were also lower 0.93 (95\% CI 0.90-0.97) in HIC immigrants than the Australian-born group, but the rates of smoking did not show any significant difference $(p=0.86)$ (Table 2$)$.

Table 2. Prevalence ratios (PRs) ${ }^{¥}$ of chronic diseases by country of birth and prevalence ratios (PRs) ${ }^{¥}$ of risk factors by country of birth.

\begin{tabular}{|c|c|c|c|}
\hline Country of Birth & Prevalence Ratio (PRs) & 95\% Confidence Interval & $p$-Value \\
\hline \multicolumn{4}{|c|}{ Chronic Diseases } \\
\hline \multicolumn{4}{|c|}{ Diabetes } \\
\hline Australian-born participants & $1.00^{\#}$ & & \\
\hline High-income countries & 1.00 & $0.99-1.01$ & 0.59 \\
\hline Low-middle-income countries & 1.02 & $1.01-1.03$ & $<0.00$ \\
\hline \multicolumn{4}{|c|}{ COPD: Emphysema/chronic bronchitis } \\
\hline Australian-born & $1.00^{\#}$ & & \\
\hline High-income countries & 0.99 & $0.98-1.00$ & 0.07 \\
\hline Low-middle-income countries & 0.98 & $0.97-0.99$ & $<0.00$ \\
\hline \multicolumn{4}{|c|}{ COPD: Asthma } \\
\hline Australian-born participants & $1.00^{\#}$ & & \\
\hline High-income countries & 0.98 & $0.96-0.99$ & $<0.00$ \\
\hline Low-middle-income countries & 0.95 & $0.94-0.95$ & $<0.00$ \\
\hline \multicolumn{4}{|c|}{ Heart diseases } \\
\hline Australian-born participants & $1.00^{\#}$ & & \\
\hline High-income countries & 0.99 & $0.98-1.01$ & 0.22 \\
\hline Low-middle-income countries & 0.99 & $0.98-1.01$ & 0.28 \\
\hline \multicolumn{4}{|c|}{ Cancer } \\
\hline Australian-born participants & $1.00^{\#}$ & & \\
\hline High-income countries & 0.98 & $0.96-0.99$ & $<0.00$ \\
\hline Low-middle-income countries & 0.93 & $0.92-0.95$ & $<0.00$ \\
\hline \multicolumn{4}{|c|}{ Risk Behaviors } \\
\hline \multicolumn{4}{|c|}{ Cigarette Smoking } \\
\hline Australian-born participants & $1.00^{\#}$ & & \\
\hline High-income countries & 0.99 & $0.87-1.12$ & 0.86 \\
\hline Low-middle-income countries & 0.75 & $0.63-0.91$ & $<0.00$ \\
\hline \multicolumn{4}{|c|}{ Insufficient Physical Activity } \\
\hline Australian-born participants & $1.00^{\#}$ & & \\
\hline High-income countries & 0.96 & $0.91-0.99$ & 0.04 \\
\hline Low-middle-income countries & 1.12 & $1.06-1.18$ & $<0.00$ \\
\hline \multicolumn{4}{|c|}{ Overweight and Obese } \\
\hline Australian-born participants & $1.00^{\#}$ & & \\
\hline High-income countries & 0.93 & $0.90-0.97$ & $<0.00$ \\
\hline Low-middle-income countries & 0.77 & $0.72-0.82$ & $<0.00$ \\
\hline
\end{tabular}

\# Reference category ${ }^{*}$ Adjusted for age, sex, education, and family income.

\section{Discussion}

This study aimed to investigate the prevalence and trajectories of chronic diseases and risk factors in mid-aged Australian-born people and immigrants from LMICs and HICs. The prevalence of diabetes mellitus and insufficient physical activity was significantly higher in LMIC immigrants than Australian-born participants and HIC immigrants. Our results also showed that the prevalence of COPD, cancer, and smoking was lower in LMIC immigrants than in the other two groups.

This study found that the prevalence ratios of diabetes were $2 \%$ higher in LMIC immigrants than in the Australian-born population (Table 2). The higher rates of self- 
reported diabetes among LMIC immigrants are consistent with earlier studies [21]. It was reported that Indian migrants had an $11.1 \%$ prevalence of type 2 diabetes than the $2.9 \%$ self-reported prevalence among the general Australian population [22]. Transitioning and adjustment of cultures in a more developed geographical environment, unhealthy diet, lower economic status, and genetic makeup of immigrants are thought to be the major contributors to high diabetes rates among LMIC immigrants [21]. Our results also showed that the prevalence of diabetes increased among HIC immigrants (5.8\% to $7.6 \%$ ) and Australian-born participants (5.2\% to 7.4\%) from 2007 to 2016 (Figure 1a). This reflects the overall increase in the prevalence of diabetes in Australia. Obesity, low education level, smoking, and physical inactivity are related to increases in the incidence of diabetes among the Australian population [23].

Our research showed that the prevalence of cancer was lower in LMIC immigrants than in the other two groups. This difference may be because of discrepancies in diet, genetic makeup, and low cancer prevalence in the country of origin. Some studies have noted that compared with the host Australian population, migrants from LMIC had a lower risk of specific types of cancers (for example, breast, lung, and colorectal cancer) related to lifestyle, but a higher risk of other types of cancers (for example, cervical and liver cancer) related to infection [24]. The "healthy migrant effect" (health advantages of an immigrant at the time of migration [25]) could partly explain the low cancer prevalence in immigrants, but since prevalence remains low with a longer duration of stay, the influence of this effect is probably marginal [26].

We found that the prevalence of COPD was also lower in LMIC immigrants than HIC immigrants and the Australian-born. Another study reported a decline in the prevalence of COPD (from 7.3\% to 7.1\%) in LMIC immigrants between 2003 to 2009, with an increase from $12.7 \%$ to $14.3 \%$ for Australian-born [21]. Despite demonstrating a similar prevalence to other studies, our data also showed some non-uniform patterns of COPD prevalence in all groups (Figure 1c,d). This variation may be due to factors such as late diagnosis, decease participants, and a decline in smoking habits [21]. Our study results also showed a decline in the prevalence of smoking. Further research may elaborate on these differences between different immigrant groups and the Australian-born population.

The present study found no significant difference in the prevalence of chronic heart diseases between immigrants and non-immigrants. This is consistent with the results presented in the Australian health inequalities report [27] and Household Income and Labour Dynamics in Australia (HILDA) longitudinal survey [21]. The HILDA study indicated an increase in the prevalence of chronic heart diseases from $26.8 \%$ to $36.5 \%$ among immigrants, and from $24.1 \%$ to $36.4 \%$ among Australian-born over the nine years. Conversely, results from an analysis of the total population of New South Wales indicated significantly lower age-adjusted cardiac disease rates in the Australian-born population than migrants from the United Kingdom and Eire, Southern Europe, and Asia [28]. One likely explanation behind the similarity of our results among all groups may be the adaptation of host country environments and westernized diet over time [29]. A scoping review of the nutritional health of immigrants reviewed 49 articles and demonstrate that southeast Asians, Caribbeans, Africans, and Latinos are at high risk for nutrition-related chronic conditions including diabetes and heart disease [30].

Our investigation found higher levels of insufficient physical activity among LMIC immigrants, at each time point from HIC immigrants and Australian-born adults. Most of the previous studies with Australian immigrants also reported high levels of physical inactivity in immigrants [29]. The higher prevalence of insufficient physical activity among LMIC immigrants could be attributed to several factors, such as cultural beliefs, health attitudes, linguistic barriers, lack of motivation, financial problems, and lack of social support [31,32]. Another likely explanation for the difference in physical activity levels of LMIC immigrants and the Australian-born cohort might be the low levels of acculturation [33]. The acculturation hypothesis suggests that the level of physical activity among immigrants is strongly associated with the ability to speak the host language and to 
engage with the host culture $[33,34]$. This hypothesis might also explain why data in our study showed that immigrants from HICs had higher levels of physical activity than LMIC immigrants, as they may have better English language skills and be more acculturated to Australian society than those born in LMIC countries [34]. Further research is required to analyze the impact of different sociocultural barriers on the physical activity levels of LMIC immigrant groups.

All groups in this study showed a decrease in the prevalence of smoking over the nine years. This is similar to the decline in smoking prevalence in Australia, overall [35]. The main tobacco control measures to date have included an increase in mass media campaigns, increases in cigarette costs, and bans on smoking in public places [36]. The lower prevalence of smoking among LMIC immigrants than Australian-born participants in this study is consistent with most of the earlier studies [37]. Protective factors such as cultural and religious beliefs, social norms, and parental pressure against adopting smoking may contribute to the lower smoking rates among LMIC immigrants [37]. On the other hand, the lack of difference in tobacco smoking rates between immigrants from HIC and Australian-born participants may be due to similar exposure to culture, language, and socio-economic profile in their country of origin and Australia.

Our study observed exponential increases in the prevalence of overweight and obese people over the nine years among LMIC immigrants, as compared to HIC immigrants and Australian-born adults. Another study reported increased levels of excessive weight in LMIC immigrants, with a positive association with the duration of residence in Australia [12]. A possible explanation for the marked increase in weight among LMIC immigrant groups is the significant adoption in different ethnic groups of obesogenic behaviors (for example, consumption of more energy-dense and nutrient-poor foods, as well as less physical activity) following migration [38]. Despite the increase in the prevalence of overweight, this study also found that the prevalence ratios of overweight and obese in the LMIC group $(0.77,95 \%$ CI $0.72-0.82)$ and the HIC group $(0.93,95 \%$ CI $0.90-0.97)$ were still significantly lower than the Australian-born $(p<0.001)$. This is consistent with a previous Australian study which reported a significantly lower relative risk of obesity $(0.81$, 95\% CI 0.79-0.83) in immigrants than the Australian-born population [11]. Another study also found that the first generation of immigrants had lower BMI than Australian-born, but had assimilated to the BMI of their host country in the second generation [39]. There is a need for research on the factors contributing to this accelerated increase in obesity in LMIC immigrants.

This study contributes substantially to the Australian immigrant health literature, particularly on risk factors and chronic diseases' differences between immigrant and non-immigrant groups. This study used a large population-based sample over nine years, and this use of longitudinal analyses addressed some limitations of previous cross-sectional research (for example, time-bound and static representation) and provided data on trajectories. This study compared the Australian-born individuals with LMIC immigrants and HIC immigrants, which provides a better understanding of risk evaluation in different groups of immigrants.

However, this research has some limitations. These longitudinal data did not include information about dietary habits, which is one of the risk factors for most chronic diseases. The prevalence data were based on self-report, which is vulnerable to bias. However, the agreement between questionnaire data and medical records is robust for well-known chronic diseases that have clear diagnostic criteria and are easily communicated to the patients [40]. There were also no data available about the length of stay in Australia of immigrants, and therefore we could not analyze the association between health outcomes with the duration of residence. As the last wave was conducted in 2016, the results presented may not reflect the current conditions, which needs to be considered when interpreting the results. 


\section{Conclusions}

This study found significant differences in the levels and trajectories of diabetes, cancers, COPD, insufficient physical activity, and overweight in LMIC and HIC immigrants and Australian-born adults. Data about chronic diseases and risk factors patterns in Australia's immigrants are important to understand health gaps and the fundamental needs of different cultural groups. Health care planning targeting high-risk health behaviors (physical activity and weight management) is needed to ensure effective intervention and to maximize the impact of available human and financial resources. Further research is needed to better understand the underlying mechanisms associated with disparities in chronic diseases and their risk factors in different immigrant groups.

Author Contributions: Conceptualization, M.N., T.L.K.-A., N.W.B. and A.K.; methodology, M.N. and A.K.; software, A.K.; validation, M.N., T.L.K.-A., N.W.B. and A.K.; formal analysis, A.K.; investigation, M.N., T.L.K.-A., N.W.B. and A.K.; resources, N.W.B. and A.K.; data curation, M.N., N.W.B. and A.K.; writing—original draft preparation, M.N.; writing—review and editing, T.L.K.-A., N.W.B. and A.K.; visualization, M.N.; supervision, A.K.; project administration, M.N. and A.K. All authors have read and agreed to the published version of the manuscript.

Funding: This research received no external funding.

Institutional Review Board Statement: The study was conducted according to the guidelines of the Declaration of Helsinki and approved by the Human Research Ethics Committee of the Queensland University of Technology. Ref. no. 3967H \& 1300000161 (25 May 2016).

Informed Consent Statement: Informed consent was obtained from all subjects involved in the study.

Data Availability Statement: The data that support the findings of this study are available on request from Gavin Turrell (gavin.turrell@rmit.edu.au).

Conflicts of Interest: The authors declare no conflict of interest.

\section{References}

1. Harris, R.E. Epidemiology of Chronic Disease: Global Perspectives; Jones \& Bartlett Learning: Burlington, MA, USA, 2013.

2. WHO. Preventing CHRONIC DISEASES A Vital Investment. 2019. Available online: https://www.who.int/chp/chronic_ disease_report/contents/part2.pdf (accessed on 12 June 2021).

3. Alwan, A. Global Status Report on Noncommunicable Diseases 2010; World Health Organization: Geneva, Switzerland, 2011.

4. Krueger, H.; Turner, D.; Krueger, J.; Ready, A.E. The economic benefits of risk factor reduction in Canada: Tobacco smoking, excess weight and physical inactivity. Can. J. Public Health 2014, 105, e69-e78. [CrossRef] [PubMed]

5. WHO. Noncommunicable Diseases Country Profiles 2018; WHO: Geneva, Switzerland, 2018.

6. AIWH. Australia's Health. 2018. Available online: https://www.aihw.gov.au/reports/australias-health/australias-health-2018 / contents/table-of-contents (accessed on 12 June 2021).

7. AIHW. Australia's Health. 2020. Available online: https://www.aihw.gov.au/reports-data/australias-health (accessed on 12 June 2021).

8. Crosland, P.; Ananthapavan, J.; Davison, J.; Lambert, M.; Carter, R. The health burden of preventable disease in Australia: A systematic review. Aust. N. Z. J. Public Health 2019, 43, 163-170. [CrossRef]

9. ABS. Migration, Australia. 2017-2018. Statistics on Australia's International Migration, Internal Migration (Interstate and Intrastate), and the Population by Country of Birth. Available online: http:/ /www.abs.gov.au/ausstats/abs@.nsf/Latestproducts/ 3412.0Main\%20Features22017-18?opendocument\&tabname=Summary\&prodno=3412.0\&issue $=2017-18 \&$ num $=\& v i e w=($ accessed on 12 June 2021).

10. Jatrana, S.; Richardson, K.; Pasupuleti, S.S.R. Investigating the Dynamics of Migration and Health in Australia: A Longitudinal Study. Eur. J. Popul. 2018, 34, 519-565. [CrossRef] [PubMed]

11. Sarich, P.E.A.; Ding, D.; Sitas, F.; Weber, M.F. Co-occurrence of chronic disease lifestyle risk factors in middle-aged and older immigrants: A cross-sectional analysis of 264,102 Australians. Prev. Med. 2015, 81, 209-215. [CrossRef]

12. Gallegos, D.; Do, H.; To, Q.G.; Vo, B.; Goris, J.; Alraman, H. Differences in cardiometabolic risk markers among ethnic groups in Queensland, Australia. Health Soc. Care Community 2019, 27, e449-e458. [CrossRef]

13. Bandyopadhyay, M.; Small, R.; Davey, M.A.; Oats, J.J.; Forster, D.A.; Aylward, A. Lived experience of gestational diabetes mellitus among immigrant South Asian women in Australia. Aust. N. Z. J. Obstet. Gynaecol. 2011, 51, 360-364. [CrossRef]

14. Hodge, A.M.; English, D.R.; O’Dea, K.; Giles, G.G. Increased diabetes incidence in Greek and Italian migrants to Australia: How much can be explained by known risk factors? Diabetes Care 2004, 27, 2330-2334. [CrossRef] 
15. Burton, N.W.; Haynes, M.; Wilson, L.-A.M.; Giles-Corti, B.; Oldenburg, B.F.; Brown, W.J.; Giskes, K.M.; Turrell, G. HABITAT: A longitudinal multilevel study of physical activity change in mid-aged adults. BMC Public Health 2009, 9, 76. [CrossRef]

16. ABS. Greater Brisbane. Available online: http://www.censusdata.abs.gov.au/census_services/getproduct/census/2016 / quickstat/3GBRI?opendocument (accessed on 12 June 2021).

17. Curtis, R.G.; Olds, T.; Plotnikoff, R.; Vandelanotte, C.; Edney, S.; Ryan, J.; Maher, C. Validity and bias on the online active Australia survey: Activity level and participant factors associated with self-report bias. BMC Med. Res. Methodol. 2020, 20, 6. [CrossRef]

18. Nelson, E.M.; Rejeski, J.W.; Blair, N.S.; Duncan, W.P.; Judge, O.J.; King, C.A.; Macera, A.C.; Castaneda-Sceppa, A.C. Physical Activity and Public Health in Older Adults: Recommendation from the American College of Sports Medicine and the American Heart Association. Med. Sci. Sports Exerc. 2007, 39, 1435-1445. [CrossRef] [PubMed]

19. WBG. Country Indebtendness Histroy. Available online: http://siteresources.worldbank.org/DATASTATISTICS/Resources/ OGHIST.xls (accessed on 12 June 2021).

20. Hirakata Vânia, N.B.A. Alternatives for logistic regression in cross-sectional studies: An empirical comparison of models that directly estimate the prevalence ratio. BMC Med. Res. Methodol. 2003, 3, 21.

21. Pasupuleti, S.S.R.; Jatrana, S.; Richardson, K. Effect of nativity and duration of residence on chronic health conditions among Asian immigrants in Australia: A longitudinal investigation. J. Biosoc. Sci. 2016, 48, 322-341. [CrossRef]

22. Anikeeva, O.; Bi, P.; Hiller, J.E.; Ryan, P.; Roder, D.; Han, G.S. The health status of migrants in Australia: A review. Asia Pac. J. Public Health 2010, 22, 159-193. [CrossRef]

23. Magliano, D.J.; Barr, E.L.; Zimmet, P.Z.; Cameron, A.; Dunstan, D.; Colagiuri, S.; Jolley, D.; Owen, N.; Phillips, P.; Tapp, R.; et al. Glucose Indices, Health Behaviors, and Incidence of Diabetes in Australia: The Australian Diabetes, Obesity and Lifestyle Study. Diabetes Care 2008, 31, 267-272. [CrossRef] [PubMed]

24. Anikeeva, O.; Bi, P.; Hiller, J.E.; Ryan, P.; Roder, D.; Han, G.S. Trends in cancermortality rates among migrants in Australia: 1981-2007. Cancer Epidemiol. 2011, 36, e74-e82. [CrossRef]

25. Kennedy, S.; McDonald, J.; Biddle, N. The Healthy Immigrant Effect and Immigrant Selection: Evidence from Four Countries; IDEAS Working Paper Series from RePEc 2006; SEDAP: Hamilton, ON, Canada, 2006.

26. Renzaho, A.M.N. Globalisation, Migration and Health; Imperial College Press: London, UK, 2016; pp. 363-389.

27. Singh Australian Health Inequalities: Birthplace. Available online: https://www.aihw.gov.au/reports/social-determinants/ australian-health-inequalities-birthplace/contents/table-of-contents (accessed on 12 June 2021).

28. Taylor, R.; Chey, T.; Bauman, A.; Webster, I. Socio-economic, migrant and geographic differentials in coronary heart disease occurrence in New South Wales. Aust. N. Z. J. Public Health 1999, 23, 20-26. [CrossRef] [PubMed]

29. Taylor, A.W.; Grande, E.D.; Fateh-Moghadam, P.; Montgomerie, A.; Battisti, L.; Barrie, H.; Kourbelis, C.; Campostrini, S. Comparison of Health and Risk Factors of Older, Working-age Australians, Italians and Italian-born Migrants to Australia, with Data from an Italian (PASSI), and an Australian (SAMSS) Risk Factor Surveillance System. J. Immigr. Minor. Health 2018, 20, 1190-1196. [CrossRef]

30. Sanou, D.; O'Reilly, E.; Ngnie-Teta, I.; Batal, M.; Mondain, N.; Andrew, C.; Newbold, B.K.; Bourgeault, I. Acculturation and Nutritional Health of Immigrants in Canada: A Scoping Review. J. Immigr. Minor. Health 2014, 16, 24-34. [CrossRef]

31. Patel, M.; Boutin-Foster, C.; Phillips, E. Understanding of cardiovascular disease risk factors among Bangladeshi immigrants in New York City. Ethn. Health 2019, 24, 432-442. [CrossRef]

32. Lassetter, J.H.; Callister, L.C. The Impact of Migration on the Health of Voluntary Migrants in Western Societies: A Review of the Literature. J. Transcult. Nurs. 2009, 20, 93-104. [CrossRef] [PubMed]

33. Evenson, K.R.; Sarmiento, O.L.; Ayala, G.X. Acculturation and physical activity among North Carolina Latina immigrants. Soc. Sci. Med. 2004, 59, 2509-2522. [CrossRef]

34. Mahmood, B.; Bhatti, J.A.; Leon, A.; Gotay, C. Leisure Time Physical Activity Levels in Immigrants by Ethnicity and Time Since Immigration to Canada: Findings from the 2011-2012 Canadian Community Health Survey. J. Immigr. Minor. Health 2019, 21, 801-810. [CrossRef]

35. Gartner, C.E.; Barendregt, J.J.; Hall, W.D. Predicting the future prevalence of cigarette smoking in Australia: How low can we go and by when? Tob. Control 2009, 18, 183-189. [CrossRef]

36. Owen, A.J.; Maulida, S.B.; Zomer, E.; Liew, D. Productivity burden of smoking in Australia: A life table modelling study. Tob. Control 2019, 28, 297-304. [CrossRef] [PubMed]

37. Joshi, S.; Jatrana, S.; Paradies, Y. Tobacco smoking between immigrants and non-immigrants in Australia: A longitudinal investigation of the effect of nativity, duration of residence and age at arrival. Health Promot. J. Aust. 2018, 29, 282-292. [CrossRef]

38. Alidu, L.; Grunfeld, E. A systematic review of acculturation, obesity and health behaviours among migrants to high-income countries. Psychol. Health 2018, 33, 724-745. [CrossRef] [PubMed]

39. Hauck, K.; Hollingsworth, B.; Morgan, L. BMI differences in 1st and 2nd generation immigrants of Asian and European origin to Australia. Health Place 2011, 17, 78-85. [CrossRef] [PubMed]

40. Burgard, S.A.; Chen, P.V. Challenges of health measurement in studies of health disparities. Soc. Sci. Med. 2014, 106, 143-150. [CrossRef] [PubMed] 